\title{
The ethics of society rather than medical ethics
}

\author{
Andrew Smith Department of Family and Community Medicine, The Medical School, Newcastle upon Tyne
}

Medicine's right to determine its own code of professional conduct used to be generally accepted because it was thought that doctors alone had the technical knowledge to understand the issues involved. This code of ethics has evolved over the centuries from the Hippocratic Oath and is about the relationship between doctors and patients. It is embodied in the Handbook of Medical Ethics published by the British Medical Association (BMA) which is written by doctors for doctors. The public have no say in medical ethics though recently the BMA has been trying to involve the public more.

Ian Kennedy in his 1980 Reith Lectures (I) questioned this right on the grounds that many of the decisions that doctors are called upon to make are not technical or clinical but moral and ethical ones. Doctors have no training in moral philosophy or ethical analysis and most of them know nothing about these disciplines. Confronted with moral decisions they treat them as though they were technical ones.

Professor Swales epitomises this kind of doctor. He believes that ethical decisions in medicine cannot be dissociated from clinical ones and the teaching of the two cannot be carried out independently. Medical ethics is too important, he believes, to have a separate place in the medical curriculum. Indeed, "the development of "medical ethics" as an identifiable subject worthy (my italics) of separate teaching ignores the fact that ethical philosophy is qualitatively different from and irrelevant to clinical teaching'. Despite this difference ethical and clinical decisions, he thinks, frequently masquerade as each other and problems have a bewildering tendency to shift from the ethical to the clinical domain. $\mathrm{He}$ cites the Arthur case as an example of this.

There is no such shift in the Arthur case. On the second day of its life the baby had symptoms of pneumonia. A clinical decision would have been to treat it. Dr Arthur did not make this decision but, having established that the parents rejected the baby, withheld treatment and the baby died. Not to treat was an ethical decision and was seen as such by the person

Key words

Medical ethics; medical education; medical ethics and the law. who reported to the police the facts of the case and treated as such by the Director of Public Prosecutions who charged Dr Arthur with murder. Not with negligence, which would have been the appropriate charge if his clinical decision had been in question. So far as Dr Arthur and the pathologist who did the first autopsy thought the baby had uncomplicated Downs Syndrome. It was only after a second pathologist with special knowledge of neonatal pathology examined the baby for the defence and described congenital defects in heart, lungs and brain which were incompatible with life, that the judge threw out the charge of murder. The charge of intention to kill was substituted and the jury rejected it unanimously. Their verdict might well have been different if they had heard only the first path ologist or if the baby had lived for several days ore weeks. The fact remains that Dr Arthur's decision not? to treat was an ethical and not a clinical one.

Professor Swales's second example of an ethical problem masquerading as a clinical one is the case of urologists refusing to dialyse elderly patients on the ground of clinical unsuitability when they know that many elderly people are eminently suitable for dialysis. There is a shortage of dialysis places and by excluding people over a certain age from consideration the pressure on those places is decreased. This is not a matter of problems masquerading as one another but a classic example of doctors treating moral problems as though they were clinical ones.

This brings us back to Ian Kennedy's argument. He asserted that the public must provide the moral and ethical framework within which doctors may legitimately use the technical and clinical skills for which they have been trained. Authoritative medical reaction was equivocal. John Havard, the secretary of the BMA, thought it quite monstrous that doctors should be subjected to such criticisms and feared that a panel of lawyers, theologians, politicians, moralists and organisations such as LIFE might decide ethical issues. Doctors, he said, intended to continue to employ their ethical principles in the best interests of their patients (2).

Michael Thomas, chairman of the BMA's ethical committee, on the other hand, thought it essential that the patient should make an informed decision: the medical profession had to initiate a movement to 
involve the public in the debate. He went on to suggest ways of doing so. They included making the Handbook of Medical Ethics generally available and providing forums for doctors and members of the public to discuss the issues and allow a consensus to emerge (3). Ian Kennedy agreed with the need to foster public participation. The trouble is that this takes time and the issue has become more urgent since the judge in the Arthur case established the legal standing of medical ethics. He said: 'Whatever ethics a profession might evolve, they could not stand up in court or survive if they were in conflict with the law' (4).

But where does the law now stand? Dr Arthur's acquittal created no precedent because of the baby's early death from natural causes. The next paediatrician who decides not to treat a malformed baby rejected by its parents is likely to face the same charge of murder. Unless, that is, autopsy reveals congenital defects incompatible with life. A baby with spina bifida, for example, may live a kind of life for years so that if it dies within days the paediatrician who did not treat it is likely to be accused of killing it. "An intention to allow a child to die much sooner than it would have done, not simply a matter of hours but of days or weeks is liable to lead to a criminal charge' (5). Getting the agreement of other paediatricians about this course of action or basing the opinion on medical ethics will not avail him if medical ethics won't stand up in court.

Doctors other than paediatricians are involved in decisions about shortening the life of the patient. General practitioners, after discussing with relatives the issue of withholding treatment from terminally ill patients who develop chest infections, often do not prescribe an antibiotic which is clinically indicated. Some, after treatment to relieve intractable pain or extreme distress in a terminally ill patient has failed, have on occasion administered a lethal dose of morphia. Others, unwilling to administer such an injection are forced to watch their patients die slowly because of a misplaced belief that the sanctity of life is absolute. In Victorian times, a predominantly Christian country did regard it as absolute - except, of course, in the case of members of the armed forces serving in a just war - but many people today hold to a utilitarian ethic and consider the issue in the context of overall harm and benefit. Some moral philosophers see no intrinsic moral distinction between killing a person with an incurable disease and allowing him or her to die in distress. They believe that faced with inevitable death doctors should ensure that it comes in the best possible way (6).

In law, however, deliberate administration of lethal doses of morphia is regarded as murder. But what about withholding antibiotics from a terminally ill patient when this is likely to lead to the patient's death days or weeks or even months sooner than otherwise? So long as the law remains obscure on this point doctors who are prepared to ensure an easier death for their patients are less likely to do so for fear of prosecution by organisations such as LIFE.

The best answer to the problem, it seems to me, is to legislate. The Abortion Act of 1967 is a good precedent for this. Termination of pregnancy, which had hitherto been a criminal act, was legalised and the conditions under which it became permissible to kill a fetus were laid down clearly in the Act. It was a good example of the public, represented by their elected members of parliament, providing, in Kennedy's words, 'the moral and ethical framework within which doctors might legitimately use their technical and clinical skills'. The majority of doctors involved - general practitioners and gynaecologists - were against the Act at the time it became law. Now opinion polls show that most of them are in favour of it and against any attempt to dilute it. A similar sort of Act setting out the conditions under which it was permissible to shorten life might well resolve our present difficulties.

Whether or not these difficulties are resolved, the present debate provides an overwhelming case for teaching ethics in medical schools. The General Medical Council (GMC) recommended in 1967 that medical ethics should be added to the undergraduate curriculum. Many schools claim that the subject is now included but few medical students are conscious of ever having been taught it. However, even if medical ethics were to be effectively taught it would be inade-? quate. Medical ethics are a professional code decided by doctors for doctors. They won't stand up in court. What needs to be taught is the ethics of society as a whole and this can be done only by bringing in specialists in moral philosophy and ethical analysis. They would not only clarify the distinction between ethical and medical decisions which confuses many doctors but would bring a leavening of the humanities into a science-based curriculum. Such study might even make medicine more of a learned profession and less of a scientific technocracy.

\section{References}

(I) Kennedy I. The unmasking of medicine. London: George Allen and Unwin, 1981.

(2) Havard J. World medicine 198I Nov 28: 108.

(3) Thomas M. Should the public decide? Fournal of medical ethics $1981 ; 7: 183$.

(4) Brahams D. Acquittal of paediatrician charged after death of infant with Down's syndrome. Lancet $198 \mathrm{I}$; ii: I IOI.

(5) Levin J. World medicine I982 April 3: 8I.

(6) Glover J. World medicine I98I Nov 28: 107 and Singer P. Practical ethics. Cambridge: Cambridge University Press, 1980: 152. 